\title{
1
}

\section{FDA Reform: Déjà Vu Encore}

\section{John J. Cohrssen}

Attorney and Counsellor at Law, 1614 North Nicholas Street, Arlington, VA, USA

\begin{abstract}
The Food and Drug Administration (FDA) creates the climate for the development of new drugs and clinical research. A 30 year struggle to bring drugs to the market more rapidly culminated in the 1992 Prescription Drug User Fee Act (PDUFA). While drug review times have shortened, concerns about drug safety possibly associated with more rapid reviews have led FDA and Congress to tighten safety requirements that may well slow or discourage clinical research. The pipeline for new drugs has been shrinking recently because of problems in the translation of fundamental research to pharmaceutical applications, according to the FDA. The FDA has therefore expanded its mandate to embark on a critical path initiative to develop the necessary translational tools. Critics including Congress, the General Accountability Office, the Institute of Medicine and the FDA's own Science Advisory Subcommittee have sharply criticized the FDA's performance, stating that the FDA's science base is inadequate and that the FDA should have greatly increased resources to hire more scientists. After almost 50 years of concern about the FDA's oversight of drugs, it is time to carefully review the structure and organization of the FDA and to consider creating a separate agency dedicated only to the regulation of medical products. To strengthen its scientific resources, the FDA should consider much greater use of non-government scientists and physicians as a more cost-effective way to acquire necessary expertise.
\end{abstract}

\section{Key Words}

FDA; PDUFA; FDA reform; drug safety; critical path initiative; FDAAA; drug lag; drug pipeline problem; streamline clinical trials; comparative effectiveness 


\subsection{Introduction}

The US Food and Drug Administration (FDA) is responsible for the safety of more than a trillion dollars worth of products each year, representing $25 \%$ of the US economy.

The FDA's management creates the climate for the development of new drugs and clinical research. The FDA imposed general standards for clinical trials, protects the rights and safety of research subjects and sets other clinical trial requirements by establishing what data are necessary to substantiate safety and effectiveness for marketing approval of a drug [1]. Drug and biologics work of the FDA is carried out by some 5000 employees, assisted by two dozen advisory committees at an annual cost of about one billion dollars.

The FDA's mission has disparate objectives for its control of drugs. Traditionally, the FDA focused primarily on drug safety, efficacy and security. Legislation enacted in 1997 added to its mission new responsibilities to help speed innovations that make medicines more effective, safer and more affordable, and to help the public obtain the accurate, science-based information they need [2]. However, the FDA has not yet demonstrated particular success in achieving these new responsibilities. Indeed, the number of drugs in the development pipeline has been shrinking and, because of safety concerns, the FDA has tightened regulatory requirements which has led to a reduction of the number of new drugs approved.

The emergence of a global economy for pharmaceuticals has complicated the work of the FDA. It no longer deals primarily with US-developed, sourced and manufactured products. Instead, it has to contend with an increasingly global environment for research and development, manufacture and import of drugs and their constituent components. Clinical trial offshoring of FDA-regulated trial sites located outside of the United States was at $41 \%$ in 2006 , up from $15 \%$ a decade earlier.

Ten years ago, the FDA reported a growing US dependence on imported pharmaceutical products. It was noted that as much as $80 \%$ of the bulk drug substances, used by manufacturers in the United States to produce prescription drugs, was imported and that the number of finished drug products manufactured abroad for the US market was increasing. In 2007, the Government Accountability Organization (GAO) observed that the United States remains dependent on foreign establishments manufacturing drugs for the US market as the value of pharmaceutical products coming into the United States from abroad continues to increase [3]. However, the FDA lacks the ability to police more than 3000 overseas drug manufacturers to ensure compliance with US requirements. Moreover, increasing adverse public health episodes have been reported due to imported counterfeit and tainted FDA-regulated products.

After a decade of successful efforts in the 1990s to more rapidly review applications for new drugs, the FDA entered the twenty-first century with a swiftly escalating focus on the safety of drugs, the integrity of clinical trial data, the insufficiency of funding and scientific staff, conflicts of interest from advisory committee members, the adequacy of new drug safety reviews, unsafe drug imports and the shrinking pipeline of new medicines. Accordingly, Congress and the FDA have recently added 
greater regulatory requirements to address widely publicized safety-related concerns. Congress and the FDA have also sought to address the 'pipeline problem' of the diminishing number of new drug applications by adding a new dimension to FDA work for facilitating the translation of scientific discovery into new medical products.

The FDA's struggle to balance early access to drugs and concerns about their safety has a long history. The 1962 Amendments to the Federal Food Drug and Cosmetic Act established the FDA's comprehensive authority to regulate human clinical trials and to approve drugs for marketing after finding substantial evidence of their safety and efficacy. Congress enacted this consumer protection in reaction to the tragic tetragenic effects of Thalidomide, resulting from its use in other countries by pregnant women to prevent nausea. Because of the FDA's caution, slow review and lack of approval for Thalidomide, its detrimental impact was much less in the United States.

After the enactment of the 1962 Amendments, and for the next 30 years, the FDA was criticized for conducting slow reviews of new drugs for marketing approval. As early as the 1970s, doctors and economists complained that the United States had a 'drug lag', i.e. that fewer new drugs were approved in the United States than in other countries with modern drug regulatory regimes and that the costs of greater regulatory control were denying the benefits of therapies to Americans. As a practical matter, the impact of a drug's slow or delayed introduction in the US market provided the FDA with an additional safety net, as the FDA could observe the safety experience of a new drug in other countries before approval in the United States.

The underlying reason for the FDA's caution was aptly described by former FDA Commissioner Alexander Schmidt in testimony before hearings held by Senator Edward M. Kennedy:

In all of FDA's history, I am unable to find a single instance where a Congressional committee investigated the failure of FDA to approve a new drug. But, the times when hearings have been held to criticize our approval of new drugs have been so frequent that we aren't able to count them... The message to FDA staff could not be clearer. Whenever a controversy over a new drug is resolved by its approval, the Agency and the individuals involved likely will be investigated. Whenever such a drug is disapproved, no inquiry will be made [4].

The FDA became less cautious in the mid-1980s, responding to political pressure from aggressive AIDS activists who campaigned for earlier and greater access to clinical trials and new drugs. AIDS patients were emphatic that they would accept higher and unknown health risks that could result from products with less clinical certainty rather than face certain death. In response, the FDA initiated the use of surrogate markers to demonstrate effectiveness as one way to speed up the drug approval process. (The surrogate marker is a substitute for a pivotal clinical measurement, typically prolongation of survival.)

When patients in an azidothymidine (AZT) clinical trial in 1986 were found to be doing much better than those in its control arms, the FDA authorized other patients to receive AZT under the compassionate use provisions of the law. (Shortly afterwards in 1987, AZT received rapid marketing approval.) Subsequently, the FDA 
established several new programs that provided more rapid availability of promising new therapies. The following list provides examples.

- In 1987, the FDA began a new program called 'treatment investigational new drugs (IND)'. Under this program, eligible subjects could receive investigational drugs for the treatment of serious and life-threatening illnesses for which there are no satisfactory alternative treatments. A treatment IND could be granted after sufficient data have been collected to show that the drug may be effective and does not have unreasonable risks provided that: (i) the drug is intended to treat a serious or immediately life-threatening disease; (ii) there is no satisfactory alternative treatment available; (iii) the drug is already under investigation, or trials have been completed and (iv) the trial sponsor is actively pursuing marketing approval.

- FDA also began a 'Parallel Track' option as a way to offer wider access to promising new drugs for AIDS/HIV-related diseases under a separate 'expanded access' protocol. This protocol parallels the controlled clinical trials that are essential to establish the safety and effectiveness of new drugs.

- In 1992 FDA established the 'Accelerated Approval' (Subpart H Approval) regime to make promising products for cancer and other life-threatening diseases available on the market on the basis of preliminary evidence such as a surrogate market prior to formal demonstration of patient benefit.

Some ten years later, responding to an increasing drumbeat of concern about drug safety, the FDA ratcheted up its efforts to ensure the safety of drugs during clinical trials and in the market place. As one critic observed, accelerated approval became 'decelerated approval' in 2003. The FDA eliminated the specific clinical development innovations that made accelerated approval possible such as single arm trial data. New requirements for randomized, double-blind, placebo-controlled clinical trials in refractory patient populations and mandatory post-approval clinical trials were also added [5].

From 2003 to 2008 concern for greater drug safety, partly because of concerns about antidepressant use in pediatric patients [6], erupted with proposals for reforms from Congress, the GAO, the Institute of Medicine and the FDA's own Science Board, among others. They made overarching recommendations to tighten safety oversight, dramatically increase resources for the FDA and improve its management by greater use of information technology (IT). They did not, however, seriously examine the foundational issues of how to improve the basic paradigm for the development and marketing of drugs in light of present and future trends in the science of drug development, and whether government is optimally structured to do this. To its credit, the FDA has initiated some steps in this direction with its Critical Path initiative.

Basic questions about the best ways for the US government to organize, structure and fund its medical products regulation remain to be critically examined. Would a dedicated medical products agency work better and be less susceptible to political pressure? What type of scientific knowledge base does a drug regulatory agency 
require for regulatory purposes? Does the FDA's approach, which relies primarily on internal staff, defeat its own goal of having the best science base when better quality scientific technical knowledge is available from outside the FDA? What is the ideal paradigm(s) for drug development considering the constantly expanding base of fundamental scientific knowledge and the need for both regulatory flexibility (to permit the advancement of scientific investigation) and regulatory certainty (to encourage investment in innovative product development)? What should the scope of drug regulation entail for safety and effectiveness, for example the translation of innovation into clinical trials and products, evidence-based health care, drug superiority and other areas? How best can the United States regulation manage to maintain the integrity of imported drugs and ingredients?

\subsection{The 1992 prescription drug user fee act adds funds and changes FDA's focus}

The chronic 'drug lag', the inadequate level of drug review staff resources at the FDA, the positive experience of more rapid access to AIDS clinical trials and new drugs and the pressure to conduct more rapid reviews of therapies for serious diseases in addition to AIDS in the early 1990s enabled the FDA to charge drug user fees to help fund the acquisition of more drug reviewers.

The FDA had long sought user fees to help fund its operations, which industry had resisted [7]. Other countries with advanced regulatory systems collect user fees for drug and medical device regulatory activities, some cover up to $100 \%$ of the costs of the regulatory agency [8].

In 1992, Congress enacted the Prescription Drug User Fee Act (PDUFA) to authorize the FDA to charge pharmaceutical manufacturers user fees, to supplement the annual FDA appropriations. In return, the FDA committed itself to achieving shorter approval time goals. These fees include an application fee, an annual establishment fee and an annual product fee. Because Congress limited authority for user fees to five years, PDUFA has been reauthorized in 1997, 2002 and 2007 by PDUFA II, PDUFA III and PDUFA IV.

Originally, the 1992 PDUFA funds could only be used for the process of reviewing new drug applications. Subsequently, Congress authorized their use for an increasing range of drug-related activities. They now support the full range of FDA activities associated with new drugs from IND application to post-marketing management and surveillance. The size of the fees has increased and they currently support more than $50 \%$ of the cost of the Center for Drug Evaluation and Research (CDER).

The FDA has become dependent on user fees. Without them, the CDER would be seriously underfunded and would be unable to function. PDUFA reauthorization has therefore become 'must pass' legislation since the Congress, administration and industry do not want FDA to be denied funds considered essential for the review of new drug applications. Accordingly, PDUFA reauthorization provides a relatively easy opportunity every five years to make changes to the law. Each reauthorization of PDUFA has brought legislative changes to the underlying Federal Food Drug and Cosmetic Act. 
- In 1997, PDUFA II added modest regulatory reforms and codified a new FDA mission.

- The 2002, PDUFA III reauthorization broadened the scope of FDA activities which user fees could fund to include preclinical to post-market surveillance for three years.

- The 2007, PDFUA IV authorized FDA to provide funds to the private sector for pursuing FDA's Critical Path Initiative. The FDA's risk management and post-marketing surveillance authority was extensively increased from earliest research through the marketing lifecycle. FDA can now impose this level of control by making approvals conditioned upon agreements by the manufacturer to conduct long-term specific Risk Evaluation and Mitigation Strategies (REMS).

PDUFA has brought unintended effects. Within the agency, for example, organizational components can be divided into the haves and have-nots. Notable differences exist in the resources and level of activity in the FDA for reviews of drugs and medical devices funded by user fees and those FDA components without user fees. In the US Senate, another unintended effect arose in 1992 because of PDUFA's tax-related aspects. The Finance Committee gained jurisdiction over FDA's drug approval activities. Accordingly, Senator Grassley, the most senior Republican on the committee, has been the Senate's strongest FDA critic, conducting extensive investigations and critical hearings and exposing highly publicized weaknesses in the FDA's drug approval process.

\subsection{PDUFA shortens drug review times and eliminates the drug lag}

By 1997, the FDA claimed that user fees had enabled the agency to reduce the 30-month average time that used to be required for a drug review before PDUFA to just 15 months. This was because of managerial reforms and the addition of 696 employees to the agency's drugs and biologics program financed by $\$ 329$ million in user fees from the pharmaceutical industry [9].

While the net result of the PDUFA has been shorter review times for new drugs, although the actual extent to which PDUFA alone was responsible for the shortening is controversial. A Brookings/American Enterprise Institute (AEI) study noted that approval times had been falling at $1.7 \%$ per year prior to implementation of PDUFA. Of the total observed decline in approval times between 1991 and 2002, approximately two-thirds can therefore be attributed to PDUFA. Much of this impact in this time period occurred in the initial years from 1992 to 1997 [10].

In 2002, the GAO observed that approval times had declined for both priority drugs (those that the FDA expect to provide significant therapeutic benefits compared to drugs already marketed) and standard drugs (those for which there are no perceived significant therapeutic benefits compared to those for available drugs). 
- From 1993 to 2001, the median approval time for new drug applications for standard drugs dropped from 27 to 14 months. The median approval time for new drug applications for priority drugs has remained stable at six months since 1997.

- However, the approval time for standard new molecular entities (NMEs), drugs containing active ingredients that have never been marketed in the United States in any form, had increased since 1998 from about 13 to 20 months. In contrast, median approval times for new biologic applications had fluctuated since 1993, ranging from a low of 12 months in 1997 to a high of about 32 months in 1995 . In 2001, the median approval time for biologic applications was about 22 months.

Finally, it is important to recognize that although drug review times have fallen, the total drug development times from drug discovery to marketing approval remains essentially unchanged. The reasons include the longer time necessary to discover NMEs and additional FDA requirements for conducting clinical trials.

\subsection{PDUFA timetables feed safety concerns}

Concerns began to be raised by 2000 that an increasing proportion of drugs approved under PDUFA timetables were withdrawn from the market for safety reasons. For example, Public Citizen, a consumer safety advocacy organization, testified on 15 September 2000 before FDA that consumers have suffered substantial harm from a large number of redundant 'me-too' drugs (e.g. Posicor, Duract, Redux and others) with known safety problems and no more effective than drugs already available [11]. Public Citizen noted in 2002 [12] that an additional three new drugs had been withdrawn from the market for safety reasons - Lotronex, Raplon and Baycol making a total of 10 drugs withdrawn from the US market since 1992 when PDUFA was enacted.

In 2002, the GAO reported to Senator Edward M. Kennedy in response to his request for a review of the impact of PDUFA on approval times and drug safety. GAO concluded that a higher percentage of drugs had been withdrawn from the market for safety-related reasons since PDUFA's enactment than prior to this, but that the size of the increase in drug withdrawal rates differs depending on the period examined. The share of more recently approved drugs (1997-2000) that have been withdrawn has risen from 1.56 to $5.34 \%$ in the period immediately after PDUFA's implementation (1993-1996). When withdrawal rates are compared for the eight-year periods before and after PDUFA, the increase is from 3.10 to $3.47 \%$. Drug withdrawals have been affected by several factors. For example, some drugs were removed from the market because doctors and patients did not use them correctly, while other drugs were found to have rare side effects that were not detected in clinical trials [13].

The FDA disagreed with the GAO's analysis and discussion of drug withdrawal rates. FDA officials said that GAO's analysis of drug withdrawals for the eight-year period preceding PDUFA compared to the first eight years of PDUFA did not show any real increase, and that GAO's analysis using the four-year groupings was significantly affected by the small number of withdrawals during each period. 
Increasing public and Congressional concerns about drug safety [14] exploded as a result of the widely-publicized alarm raised about cyclooxygenase (COX)-2 inhibitors (e.g. Vioxx and Celebrex), selective serotonin reuptake inhibitors (SSRIs) and Ketek. Congress held multiple hearings on the safety of these drugs and the adequacy of FDA reviews, including testimony from an FDA whistleblower.

A 2006 GAO report stated that the FDA lacks clear and effective processes for making decisions about, and providing management of, post-market safety issues. The process has been limited by a lack of clarity about how decisions are made and about organizational roles, insufficient control by management and data constraints. GAO observed that there is a lack of criteria for determining what safety actions to take and when to take them [15].

A 2007 Institute of Medicine (IOM) report stated that the drug safety system was impaired by the following factors: serious resource constraints that weaken the quality and quantity of the science that is brought to bear on drug safety; an organizational culture in CDER that is not optimally functional; and unclear and insufficient regulatory authorities, particularly with respect to enforcement [16].

In late September 2007, the Health and Human Services (HHS) Inspector General issued a scathing report stating that the FDA does little to ensure the safety of persons who are clinical trial subjects. As reported in the New York Times, the inspector general said that 'federal health officials did not know how many clinical trials were being conducted, audited fewer than $1 \%$ of the testing sites and, on the rare occasions when inspectors did appear, generally showed up long after the tests had been completed' [17].

Both the GAO and IOM made recommendations to add greater drug safety requirements and more post-market surveillance. IOM urged a much greater FDA role in surveillance and offered a broad list of recommendations for greater pre- and post-market risk management and other purposes. Likewise, GAO recommended that the Congress consider expanding FDA's authority to require drug sponsors to conduct post-market studies when needed, track post-market drug safety issues, revise and implement its draft policy on major post-market safety decisions, improve the dispute resolution process and clarify the office of drug safety's role in scientific advisory committees.

Professor Daniel Carpenter and associates tied the issue of safety to the requirements of PDFUA reviews [18]. They claimed that the PDUFA clock has dramatically influenced FDA review behavior such that a high proportion of approvals are concentrated in the months and weeks just before the deadline, and relatively few occur shortly afterwards. PDUFA deadlines appear to influence FDA decisions that may have an impact on drug safety. Based on an analysis of six measures, including frequency of labeling revisions and safety-based withdrawals from the market, they claim, 'the rate at which drugs experience post-marketing regulatory events is appreciably higher for drugs approved in the months before the PDUFA clock deadlines, compared to others'.

John Calfee of the American Enterprise Institute strongly disagrees with the conclusion that FDA safety had been compromised. Calfee states that 'despite its influence and provenance, the IOM report was deeply flawed' [19]. One problem is 
that none of the authors were drug development specialists, which virtually guaranteed that the exigencies of new drug development would be slighted in comparison to drug safety. Worse, the report was remarkably unacademic and provided only cursory scientific support for much of its analysis and recommendations. He argues that the drug safety crisis never existed because (i) the facts do not support the safety claims alleged for the specific drugs of concern or (ii) the risks are greater for newer drugs than older ones. He further raises concerns about the risks that will result for the FDA and the public from the unnecessary expansion of FDA powers, and how that could further discourage new drug development.

\subsection{FDA responds to safety concerns}

According to Stephen Mahinka [20], the FDA responded to the safety concerns with various actions by:

- increasing its rate of rejections and delays of new drug applications because of safety concerns

- requiring phase IV studies as a condition of a new drug approval

- $\quad$ issuing safety alerts

- issuing more public health advisories requiring label revisions/warnings

- $\quad$ suggesting additional clinical trials

- imposition of restricted distribution programs

- removal of previously approved indications

- market withdrawals.

Moreover, the FDA initiated further actions regarding drug safety by:

- establishing a new Drug Safety Board (March 2007) to provide independent management and advice to FDA on drug safety issues and disseminating safety information

- establishing new associate directors for safety in all 17 FDA drug review divisions

- initiating a new pilot program to prepare safety profiles for several approved NMEs

- establishing a new Risk Communication Advisory Committee to assist the Agency in communicating risks and benefits to the public 
- initiating planning to integrate genomic information into drug prescribing

- issuing a new FDA Drug Safety Newsletter (September 2007) to report early safety findings.

\subsection{The pipeline problem}

In 1993, US pharmaceutical research and development (R\&D) spending began to surpass the amount of money spent by the National Institutes of Health (NIH) on biomedical research. By 1997, the number of applications for NMEs and biologics license applications (BLAs) received by FDA began to decline, as shown in Figures 1.1 and 1.2.

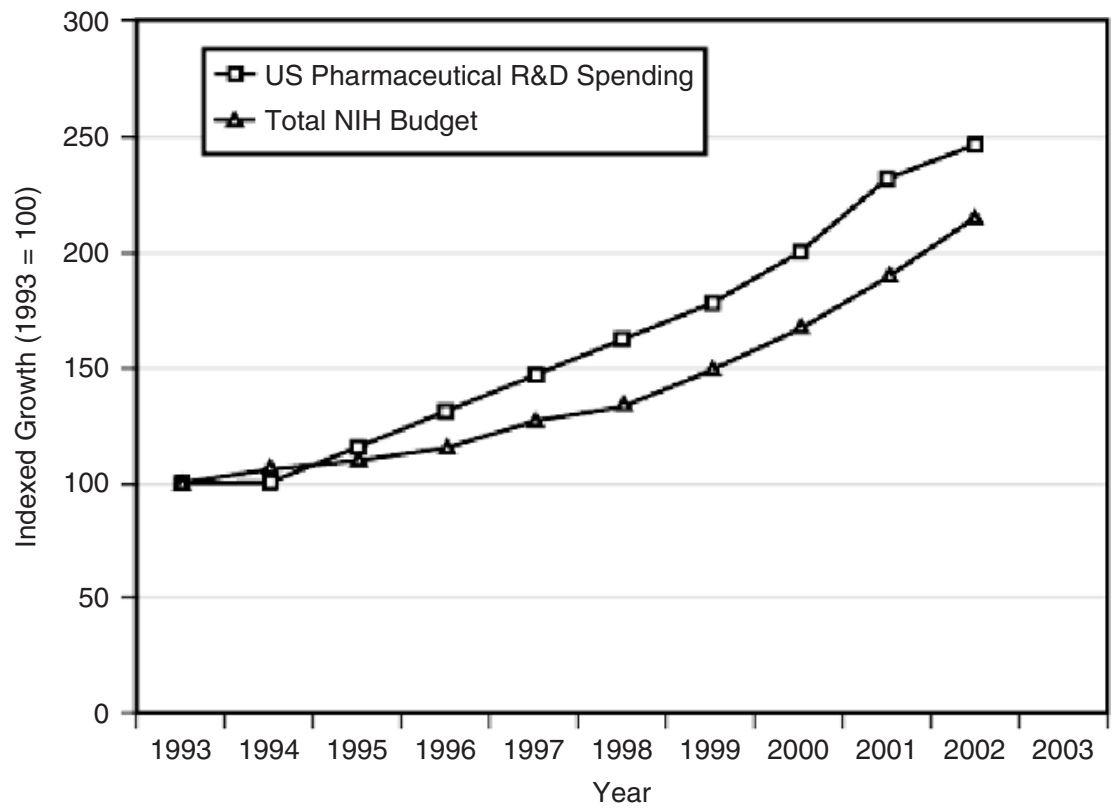

Figure 1.1 Ten-year trends in biomedical research spending. The figure shows 10-year trends in biomedical research spending as reflected by the NIH budget (Budget of the United States Government, appendix, FY 1993-2003) and by pharmaceutical companies' research and development (R\&D) investment. (Source: PAREXEL's Pharmaceutical R\&D Statistical Sourcebook 2002/2003.)

In 2002, the Department of HHS began its own initiatives to accelerate the development of new medical products. Dr Elias Zurhouni, the new Director of the NIH, convened a series of meetings to chart a 'roadmap' for medical research in the twenty-first century, particularly translational research.

This process was designed to ask the kind of probing questions that a complex research organization should periodically pose, especially when in transition. The roadmap was 


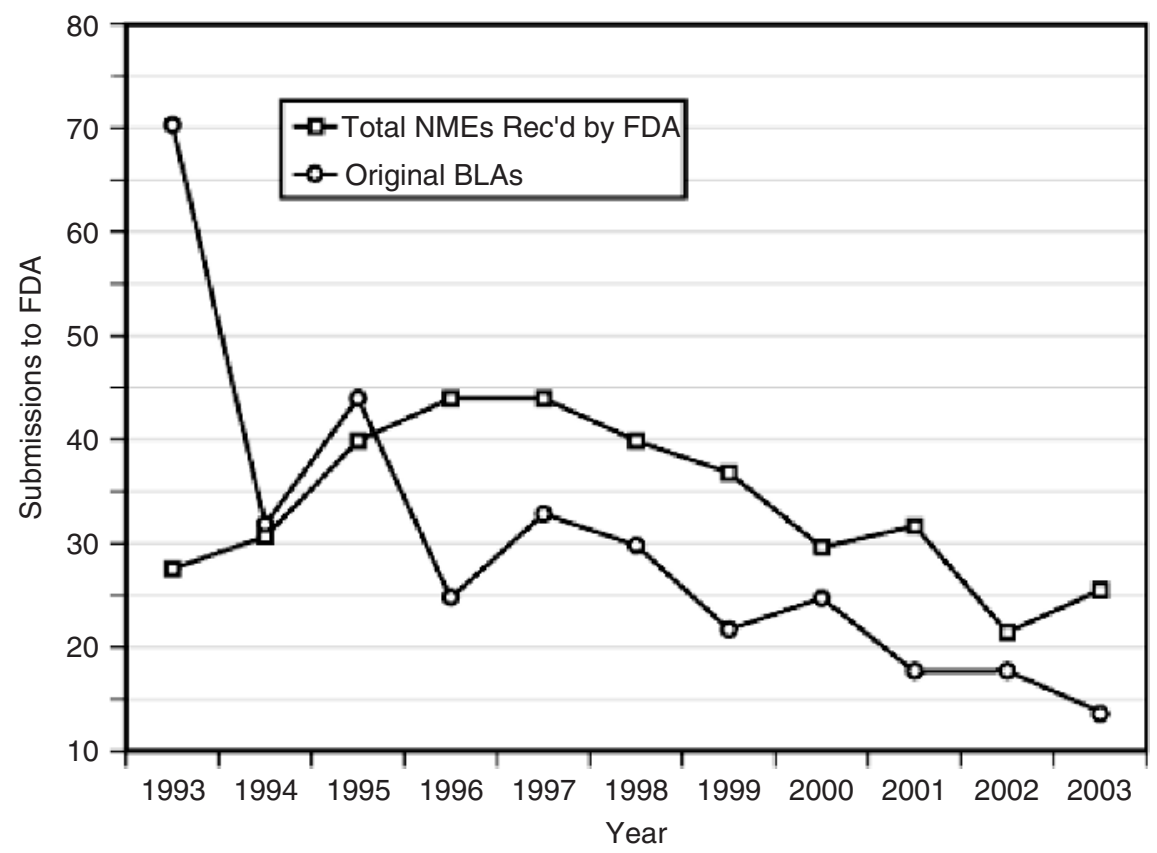

Figure 1.2 Ten-year trends in major drug and biological product submissions to FDA. The figure shows the number of submissions of NMEs (drugs with a novel chemical structure) and the number of biologics license application (BLA) submissions to FDA over a 10-year period. Similar trends have been observed at regulatory agencies worldwide. (Source: FDA, Innovation or Stagnation: Challenge and Opportunity on the Critical Path to New Medical Product, March 2004.)

purposefully focused on efforts that no single or small group of institutes or centers could or should conduct on its own, but that NIH as a whole must address to ensure both efficient and effective discovery. The goal was to define a compelling, limited set of priorities that can be acted on and are essential to accelerate progress across the spectrum of the institute missions [21, 22].

A year later in early 2003, the newly appointed FDA Commissioner Mark McClellan started an effort to improve the development and availability of innovative medical products by improving new product reviews and facilitating new products through clearer, up-to-date guidance for particular diseases and for emerging technologies. The FDA noted a worldwide trend in fewer applications for review of NMEs.

Explanations cited include a weakened investment climate, a trend toward development of relatively minor improvements in types of drugs already on the market, concerns that companies are only interested in products that have the potential to be 'blockbusters', and additional time required for product developers to cope with a 'deluge' of new basic scientific findings in such advanced areas as genetics, genomics, and proteomics. FDA is also cited for the declining application rate, by some who believe that the agency is becoming more conservative in the face of recent drug withdrawals 
(although the rate of drug withdrawals has not risen over past years), and that FDA desires to seek increasingly more data about a drug, thus causing larger and longer study trials that consume drug development resources. In addition, recent research has shown that the cost of developing a new drug has increased considerably [23].

The FDA proposed to reduce product development times by (i) reducing delays and cost in product approvals by avoiding multiple review cycles and (ii) improving the review process through a quality systems approach to medical product review. The FDA also proposed plans to enhance three key areas of emerging technology: cell and gene therapy; pharmacogenomics/pharmacogenetics and novel drug delivery systems; and collaborative clinical guidance development.

In 2004, the FDA announced a broader Critical Path Initiative to stimulate and assist a national effort to modernize the scientific process (the 'critical path') through which FDA-regulated products are developed, evaluated and manufactured. The FDA wanted to improve the critical route from medical discoveries in the laboratory to consumers more efficiently. The Critical Path Initiative would be a collaborative effort between government, industry and academia.

The 2004 FDA report Challenge and Opportunity on the Critical Path to New Medical Products blamed the applied sciences for the lack of new tools to obtain fundamentally better answers about how the safety and effectiveness of new products can be demonstrated in faster timeframes, with more certainty and at lower costs.

In many cases, developers have no choice but to use the tools and concepts of the last century to assess this century's candidates. As a result, the vast majority of investigational products that enter clinical trials fail. Often, product development programs must be abandoned after extensive investment of time and resources. This high failure rate drives up costs, and developers are forced to use the profits from a decreasing number of successful products to subsidize a growing number of expensive failures. Finally, the path to market even for successful candidates is long, costly, and inefficient, due in large part to the current reliance on cumbersome assessment methods [24].

According to FDA's Janet Woodcock, there had been an explosion of scientific discoveries that can help produce more and better medical products. 'But the efficiency for scientific discoveries being translated into medical products is very low - in fact, it's worse than it was 10 years ago. . Today, new compounds that make it through Phases 1 and 2 of clinical trials fail $50 \%$ of the time in Phase 3 compared to a $20 \%$ failure rate 10 years ago' [25]. To develop medical products more efficiently, Dr Woodcock responded that:

We need better tools to predict and detect safety problems early in the Critical Path so that products likely to fail are weeded out and developers can focus on products with a high probability of safety and effectiveness. We also need tools to guide the sponsor of a drug in choosing the appropriate dose and regimen or, in the case of a medical device, the right size and placement. And manufacturers need tools to better mass-produce an approved medical product, such as a vaccine, and evaluate the quality of the finished product... So we need to build a better tool kit. And the tools must be made publicly available for use by all researchers and product developers. 
The FDA's Critical Path initiative began slowly, as noted in the trade press almost two years later in January 2006:

The [critical path] white paper was written with a sense of urgency, and issued with fanfare. A list of research priorities was promised within a matter of months. And then ... seemingly nothing. The "research opportunities" list never appeared, and Critical Path seemed to drop off the radar as public concern veered in the direction of drug safety, and politicians railed about the "too-cozy" relationship between FDA and the industry. As recently as this fall [2005], Critical Path looked dead or close to it [26].

In March 2006, the FDA issued the Critical Path Opportunity Report with a list of research opportunities intended to improve product development in the short- and mid-term. The report presented 76 specific scientific opportunities that FDA stated 'if undertaken, would provide a starting place for collaborative work on modernizing the critical path sciences'. The opportunities were organized into six priority topics and were identified through 'extensive outreach with patient groups, health-related organizations, the pharmaceutical industry, academia and other federal agencies'.

In June 2008, the FDA published the key FDA Critical Path Activities underway in 2007. FDA lists these activities in six categories as follows.

1 Better evaluation tools. Biomarker development is a major focus. A new generation of predictive biomarkers would dramatically improve the efficiency of product development, help identify safety problems before a product is on the market (and even before it is tested in humans) and facilitate the development of new types of clinical trials that will produce better data faster.

(a) FDA is a founding member of the public/private Biomarkers Consortium that seeks projects to aim to search for and validate new biomarkers to accelerate the competitive delivery of successful new technologies, medicines and therapies for prevention, early detection, diagnosis and treatment of disease.

(b) FDA, NCI, NIH and the Centers for Medicare and Medicaid Services (CMS) formed the Oncology Biomarker Qualification Initiative (OBQI) - an agreement to collaborate on improving the development of cancer therapies and the outcomes for cancer patients through biomarker development and evaluation.

(c) FDA issued industry guidance in May 2007, Clinical Trial Endpoints for the Approval of Cancer Drugs and Biologics, that provides recommendations to applicants on endpoints for cancer clinical trials submitted to FDA to support effectiveness claims in new drug applications, BLAs or supplemental applications. It also provides background information and discusses general regulatory principles. The endpoints discussed in this guidance are for drugs to treat patients with an existing cancer. This guidance does not address endpoints for drugs to prevent or decrease the incidence of cancer. FDA plans to prepare guidelines for endpoints for specific types of cancer.

(d) FDA will seek to better detect and react to safety issues through risk minimization action plans and REMS. 
2 Streamlining clinical trials. Reforming the clinical trial process - both design and trial conduct - would dramatically improve the efficiency of product development.

(a) Adaptive clinical trials allow those engaged in drug development to respond to what they learn about the safety and potential benefits of new medicines in the development process by making modifications to treatment, endpoint or target population during testing. These tools may help arrive at a positive conclusion about an effective treatment with exposure of fewer patients in the testing process. They also allow drug developers to spend less time and money discovering that a new treatment does not work or must be discarded because of a high incidence of serious side effects.

(b) Exploratory IND studies were the subject of a January 2006 guidance designed to facilitate very early exploratory scientific studies in people before the standard safety studies (phase 1) begin. Because only small amounts of drugs are used in these early studies, they represent fewer potential risks for people in these trials. The guidance makes recommendations about safety testing, manufacturing and clinical approaches that can be used in these very early studies. The guidance explains how medical researchers can take full advantage of the flexibility built into existing regulations in the amount of data needed when asking the FDA's permission to proceed with such a study, enabling more rapid delivery of innovative products to patients.

(c) Personalized medicine and pharmacogenetics will allow decisions on which patients should receive what drug and in what dose to determined based on genetics.

3 Harnessing bioinformatics. The application of mathematics, statistics and computational analysis to biological information holds the potential to reduce the size and scope of human and animal trials while improving development efficiency and predictability of results. For example, the concept of model-based drug development holds vast potential to support more efficient and effective development of drugs and medical devices.

4 Moving manufacturing into the twenty-first century. The ability to reliably manufacture a high-quality product on a commercial scale is a frequent stumbling block. Critical path tools that help identify and analyze critical product attributes hold the potential to improve both manufacturing efficiency and quality.

5 Developing approaches to address urgent public health. Needs include antibiotics and counter-measures to combat emerging infections and bioterrorism. Rapid methods for identifying infectious agents will improve our ability to develop new treatments and to respond to emergencies. Models are needed to test new treatments when testing in humans is unethical.

6 Specific at-risk populations-pediatrics. This will combine and analyze data from existing pediatric studies and look to new genomic technologies for improved diagnosis and treatment of adolescent depression. In addition, 
infections in newborns are a significant public health problem and pose difficult development issues that could be overcome with better animal models.

The Critical Path Opportunities report also listed the need to clarify the regulatory process and to build a national infrastructure that will support and continually improve the critical path sciences. For example, the critical path needs academic programs in experimental medicine as well as clinician researchers who can work effectively in the laboratory as well as with animal and human studies.

Updates to the Critical Path List are available on the FDA Critical Path web site [27].

\subsection{The 2007 FDA Science Board's Subcommittee on Science and Technology report}

In December 2006, FDA Commissioner Andrew C. von Eschenbach requested that the Science Board, an advisory committee to the commissioner, form a subcommittee to assess whether science and technology at the FDA can support current and future regulatory needs. Specifically, the subcommittee's charge was to identify the broad categories of scientific and technologic capacities that the FDA needs to fully support its core regulatory functions and decision making throughout the product life cycle, today and during the next decade. The Science and Technology Subcommittee of the FDA Science Board was composed of three members of the Science Board and other experts representing industry, academia and other government agencies, and included individuals with extensive knowledge of cutting-edge research.

The report [28] was a scathing assessment of the FDA's capabilities with the following overarching conclusions.

- The FDA cannot fulfill its mission because its scientific base has eroded and its scientific organizational structure is weak.

- The FDA cannot fulfill its mission because its scientific workforce does not have sufficient capacity and capability.

- The FDA cannot fulfill its mission because its IT infrastructure is inadequate.

The subcommittee found that these deficiencies have two sources.

- The demands on the FDA have soared due to the extraordinary advance of scientific discoveries, the complexity of the new products and claims submitted to FDA for pre-market review and approval, the emergence of challenging safety problems and the globalization of the industries that FDA regulates.

- The resources have not increased in proportion to the demands. The result is that the scientific demands on the agency far exceed its capacity to respond. 
This imbalance is imposing a significant risk to the integrity of the food, drug, cosmetic and device regulatory system, and hence the safety of the public.

The subcommittee further noted that the impact of the deficiency is profound precisely because science is at the heart of everything the FDA does. The Agency will flounder and ultimately fail without a strong scientific foundation. That foundation rests on three pillars.

1 Strong selective scientific research programs that are appropriately missionsupportive, in all areas of FDA responsibility. This research is critical because it is not conducted by other public or private entities, but is fundamental to the discharge of FDA's statutory responsibilities to protect and promote the public health.

2 Excellent staff with cutting-edge scientific expertise appropriate to the mission. This expertise includes the ability to access, understand and evaluate science; effectively apply this science to the regulatory process; and communicate the implications of its findings for product safety and efficacy to the public.

3 An information infrastructure and processing capability that ensures the FDA has access to the best data and information necessary to support the regulatory science required to fulfill the FDA's mission.

The subcommittee argued for vastly increased resources for the FDA for science but provided no specifics other than the obvious conclusion that 'FDA must have the scientific staff and resources to undertake the regulatory research that will provide a basis to: (1) improve capacity for safety and efficacy evaluations and monitoring of candidate and licensed products, (ii) modernize current regulatory pathways and (iii) develop new regulatory pathways where there are currently none'.

The subcommittee also claimed that this research must be undertaken by FDA because it is mission critical, and because it either cannot or will not be done by other government agencies or industry.

The subcommittee did note that more than resources alone would be necessary, but without resources FDA would clearly fail to deal with its precarious situation.

\subsection{The FDAAA of 2007 reauthorize PDUFA and provide new authority to address safety and the critical path initiative}

The Food and Drug Administration Act Amendments of 2007 (FDAAA) included the reauthorization of PDUFA IV and changes to user fees, FDA's pre-market review of drugs and post-marketing drug safety requirements. Included here are only drug-related provisions of PDUFA IV and the FDAAA [29].

The PDUFA IV amendments for pre-market review performance goals do not differ significantly from PDFUA III. In its commitment for PDUVA IV funding, the 
FDA agreed to complete several guidance documents. The new performance goals include the development of a new five-year plan to modernize FDA's drug safety and pharmacovigilance process. The FDA will also seek to reduce medication name confusion with new priority name review initiatives.

PDUFA IV substantially increases the way that FDA can spend user fees to pursue drug safety. Originally only PDUFA I authorized the use of user fee revenues for the review of human drug applications. The 2002 Amendments added limited authority for safety-related activities, namely collecting, developing and reviewing safety information on drugs approved, including adverse event reports, during a period of time after approval of such applications or supplements (not exceeding three years). PDUFA IV removed the three year restriction, thus permitting the use of user fees for the full range of post-market activities including the development and use of improved adverse-event data collection systems and improved analytical tools to assess potential safety problems.

The 2007 amendments expanded the exemption of orphan drugs from the annual product and establishment fees. PDUFA had previously exempted orphan drugs from application fees. Similarly, the FDA may waive or reduce user fees when necessary to protect public health.

The 2007 amendments also reauthorized and amended the 2003 Pediatric Research Equity Act (PREA). PREA had required that most applications for drugs or biologics include a pediatric assessment. Now a new event reports on products whose labeling has changed as a result of pediatric assessment. Similarly, the amendments reauthorize and amend the 2002 Best Pharmaceuticals for Children Act (BPCA). BPCA gives an additional six months of exclusivity or patent protection for new and currently-marketed drugs when applicants conduct pediatric studies on products identified by FDA. The 2007 change added preclinical studies to pediatric studies and shortens the time for sponsors to qualify for exclusivity.

The 2007 amendments addressed concerns about the integrity and transparency of the drug trials and their review. The amendments provide the public with much expanded access to information about clinical trials and their results. The ClinicalTrials.gov database has expanded from only drug trial information on INDs for serious and life-threatening diseases or conditions to all diseases and conditions. In addition, a second database will be established to include results and adverse events on all trials that form the basis of an efficacy claim or are conducted after a drug or device is approved. New conflict of interest rules for FDA advisory committees also were added to promote integrity and transparency.

FDAAA authorized a way to fund FDA's Critical Path initiative. It established the Reagan-Udall Foundation for the FDA, a non-profit corporation to advance FDA's Critical Path Initiative and to identify and address unmet scientific needs in the development, manufacture and evaluation of the safety and effectiveness of FDA-regulated products, including post-market evaluation.

The FDAAA's most expansive provisions responded to concerns about the safety of drugs after approval. The law gives the FDA new authority to require post-approval studies and clinical trials, to request that safety information be added to labeling and to require the submission and performance of a REMS. 
FDA is given broad authority to require post-market studies or clinical trials 'on the basis of scientific data' deemed appropriate by the FDA, 'including information regarding chemically related or pharmacologically-related drugs' to assess a known serious risk or signals of a serious risk or to 'identify an unexpected serious risk when available data indicates the potential for a serious risk'.

REMS adds substantial new authority. The FDA can require REMS during clinical development or post-approval if FDA determines that specific interventions are needed to ensure that benefits outweighs the risks. The REMS must be submitted with the application for the review of a new drug. Items of consideration for products in clinical development include:

- estimated size of likely patient population

- seriousness of disease or condition

- $\quad$ expected benefit of the drug

- expected duration of treatment

- seriousness of known or potential adverse events

- whether the drug is an NME.

For approved products, criteria can include new safety information that emerges after approval. This includes clinical trial data, adverse event reports, post-approval studies, peer-reviewed literature, risk identification and analysis system or other means about:

- a serious risk or unexpected serious risk that arises after drug approval, REMS required or last REMS assessment or

- effectiveness of the approved REMS (since the last assessment).

FDAAA establishes new civil penalties for violations of these safety requirements. These are capped at $\$ 250000$ per violation or up to a maximum of $\$ 1000000$ for all violations in a single proceeding with additional penalties for continuing violations.

Finally, in response to concerns that had been raised regarding direct to consumer advertising (DTC), the amendments authorized a new Pre-review of Television Advertisements program with a new user fee. However, because the program failed to reach mandated revenue targets and Congress had not provided other funds for it, the FDA issued a notice in January 2008 that the program would not be implemented because the user fees for the program were not provided. FDA is now authorized to impose civil penalties for DTC advertising that is false and misleading, up to $\$ 250000$ for the first offense and $\$ 500000$ for a subsequent offense. A DTC advert that had gone through the now dormant pre-review program would have been exempt from civil penalties. 


\subsection{The impact of PDFUA on FDA}

PDUFA has not only speeded up the review times for new drugs, but also made fundamental changes to the Center for Drug Evaluation and to the entire FDA. CDER no longer lacks the resources to complete reviews quickly and PDFUA funds can now be used for safety reviews. Industry found the cost of user fees of $\$ 900000$ in 2006 to be an acceptable cost, considering the previous cost of some $\$ 10$ million lost for each month of delay.

User fees help provide the resources to expand efforts for the safety of products and assist the Critical Path Initiative. The FDA's role has therefore ventured into new territory in the efforts to facilitate the translation of research into new products through new tools and approaches to clinical trial development. Post-marketing surveillance also expands the FDA's ability to monitor the use of products in the general population.

The user fees available for drugs and medical devices have created a split within the FDA. Those parts of the FDA without user fees are the poor siblings of the user-fee-funded components. Even within CDER, the non-user-fee-funded activities, such as generics, are claimed to receive less attention. Also, because user fee revenues do not cover certain unanticipated cost increases in user-fee-funded activities, appropriated funds from other parts of FDA have had to subsidize this shortfall.

While industry and certainly patients benefit from the availability of new therapies from more rapid reviews, critics complain that by becoming dependent on industry funding, FDA has lost a degree of flexibility and objectivity in its ability to deal with industry. These critics claim that simply receiving industry money creates an appearance of a conflict of interest and places subtle pressures on the FDA. They complain that industry and FDA negotiated the user fee drug review goals required by the PDUFA program through a non-transparent process. They argue that FDA has lowered its safety standards, as is evidenced by claimed increases in the number of products with problems and market withdrawals. Moreover, some believe that merely speculating on the possibility of suboptimal reviews can threaten public confidence in FDA reviews. Adding to the debate are allegations of FDA staff of pressure to meet performance goal deadlines, suggesting to some that safety and effectiveness data are being inadequately evaluated [30].

Other countries and the European Union have user-funded drug regulatory agencies that do not come under these attacks of industry bias. Some of these agencies receive all or most of their funding from user fees [31].

\subsection{Comparative medical benefits, comparative effectiveness and FDA}

Comparative medical benefits and comparative effectiveness will most likely have a much expanded emphasis by the US government and this will impact pharmaceutical R\&D and the FDA. The Obama administration has expressed broad support for increased access to health insurance and administration officials strongly support 
comparative studies as a way to determine the value of medical products and to control their costs.

Peter R. Orzag, director of the White House Office of Management and Budget, testified before the Subcommittee on Health in 2007 on the comparative effectiveness of medical treatments while director of the Congressional Budget Office. He concluded at the hearing that comparative clinical effectiveness research, combined with changes in payment incentives, 'offers a promising mechanism for reducing health care costs to a significant degree over the long term while maintaining or improving the health of Americans', while emphasizing that significant cost savings from such research would not been seen for many years [32]. While many want to see more comparative effectiveness results for pharmaceuticals, others are wary that comparative clinical effectiveness research is neither necessarily well designed nor sufficiently sensitive to individual differences, and is biased to concluding that cheaper drugs are more effective.

Comparative effectiveness faces many challenges in defining how it is measured, how research is conducted and how to interpret results. For example, effectiveness (use in the medical practice population) differs from efficacy (use in the ideal condition of clinical trials). How should costs be measured - total costs, drug costs, etc.? Are costs monetized (cost benefit) or are they non-monetized (cost effectiveness). The quality and definition of cost effectiveness will vary depending on how results are to be used - for a patient's decision, for an insurance company decision a formulary decision or for government, etc.

The US government has various programs related to comparative effectiveness within HHS, the Veterans Administration and the Department of Defense. HHS's Agency for Healthcare Research and Quality (AHRQ) and the NIH are currently the largest federal bodies funding extramural health technology assessments. AHRQ has several ongoing programs for health technology assessments. It funds pharmaceutical outcomes in a national demonstration program for education and research on the optimal use of drugs, biologicals and medical devices through the Centers for Education and Research on Therapeutics. The program is administered by AHRQ in consultation with the FDA. Some of the research is also conducted in partnership with private corporations, such as insurers or pharmaceutical manufacturers. The research compares the health risks, benefits, cost-effectiveness, economic implications and interactions of treatments.

AHRQ also conducts research for the CMS under Section 1013 of the Medicare Prescription Drug, Improvement and Modernization Act of 2003. This law authorizes research, demonstrations and evaluations to improve the quality, effectiveness and efficiency of the Federal-administered Medicare program and two programs for which funding and administration is shared with the States: Medicaid and the State Children's Health Insurance Program (SCHIP). The law prohibits the Administrator of CMS from using the data produced under the section to withhold coverage of a prescription drug.

The Veterans Health Administration's Pharmacy Benefits Management Strategic Healthcare Group and the Department of Defense PharmacoEconomic Center (PEC) conduct their own assessments to make formulary and pricing decisions [33]. 
Recently comparative effectiveness has increasing support from the US Congressional Budget Office, the Congressional Research Service, the Institute of Medicine and the Medicare Payment Advisory Commission [34].

In response to the 2009 economic crisis, the government's 'stimulus package' contained 1.1 billion dollars of new funding for comparative clinical effective research. The funding is to be used for additional research and to accelerate 'the development and dissemination of research assessing the comparative clinical effectiveness of health care treatments and strategies, including through efforts that: (i) conduct, support or synthesize research that compares the clinical outcomes, effectiveness and appropriateness of items, services and procedures that are used to prevent, diagnose or treat diseases, disorders and other health conditions and (ii) encourage the development and use of clinical registries, clinical data networks and other forms of electronic health data that can be used to generate or obtain outcomes data'. The stimulus package also establishes a Federal Coordination Council for Comparative Clinical Effectiveness composed of senior government officials from agencies that support health care services, treatment and regulation of medical products (FDA).

\subsection{FDA and non-inferiority trials}

While the FDA does not have specific authority to request superiority studies, it does consider non-inferiority trials as the norm in certain situations, for example when it is inappropriate to use a placebo control [35]. 'These situations overlap substantially with situations in which you need some degree of comparative data because lesser effectiveness would be dangerous, a safety issue and not a relative effectiveness issue (because FDA does not have authority for those).' Other examples include anti-infective trials, some cancer trials and cardiovascular trials where the outcomes with the standard are known and a lesser effect of a new drug would be unsafe.

FDA did not approve Arcoxia, a 'me-too' drug, which had been rejected by the FDA Arthritis Advisory Committee because its safety profile was inferior [36]. At a press conference following the vote, Robert Meyer, M.D., M.P.H. of the FDA's CDER, said he came away with the opinion that the advisory committee intended its vote to resonate beyond Arcoxia. The message, Dr Meyer said, is that the FDA should no longer approve 'just another product in a class if it has the same level of risk as existing products and does not offer a unique benefit' [37].

The FDA also can request the cessation of marketing a drug for safer alternatives, for example Pfizer's Rezulin for new alternatives Avandia and Actos.

Superiority studies are sometimes submitted to demonstrate efficacy for non-responders, particular for a toxic approval of a drug otherwise too toxic unless it has a clear clinical advantage, such as Clozapine for schizophrenics.

Other agencies do pursue comparative studies. For example, the NIH conducted a comparatives effectiveness study of two Genentech drugs, Lucentis and Avastin. 


\subsection{FDA and CMS decisions on Medicare coverage}

FDA decisions impact Medicare coverage decisions and coverage decisions impact the pharmaceutical industry and R\&D interest. For qualified clinical trials, Medicare (administered by the CMS) covers routine patient care costs for reasonable and necessary items and services to diagnose/treat complications arising from trial participation when certain conditions are met. New product developers will likely increasingly seek to qualify for CMS coverage, by tailoring clinical trials to fit CMS requirements.

CMS coverage decisions are based on a determination of what is reasonable and necessary for the diagnosis or treatment of an illness or injury, which is different from FDA's safety and efficacy standard. Accordingly, CMS is increasingly considering ways to contain costs. For example, when FDA added a 'black box' warning to the label for Aranesp, Epogen and Procrit with instructions for the doctor to prescribe the lowest dose necessary to keep the patient from needing a blood transfusion, CMS restricted coverage based on the FDA 'black box' concerns. When asked by Congress whether this was appropriate, FDA supported CMS as consistent with the available scientific data.

Moreover, CMS has argued in court that CMS 'can set the payment rate by deciding which expenses, associated with the covered item, are reasonable and necessary' [38].

\subsection{Preemption: FDA's role in relation to liability litigation in state courts}

The FDA is expanding the extent of its influence on consumer protection in liability actions after products are on the market. Two recent cases deal with whether FDA's marketing approval is sufficient to preempt state laws which have in the past permitted liability suits against manufactures and providers of products associated with untoward results. On 20 February 2008, the Supreme Court ruled that a plaintiff may not sue under state law to challenge the safety or effectiveness of a medical device to which the FDA has given 'premarket approval' [39]. A parallel case is currently awaiting a Supreme Court decision about whether the same preemption would apply to a drug product [40]. If the Supreme Court rules in favor of FDA preemption for pharmaceuticals, the additional impact of FDA regulatory decision making as the sole determinant of drug safety will likely add to the weight of responsibility already felt by reviewers, and could encourage more risk-adverse decision making. However, Congress could seek to reverse the Supreme Court by legislation.

\subsection{FDA's exclusivity in allowing access to experimental drugs}

A recurrent theme in FDA's history is the extent to which an individual has the right to use an unapproved pharmaceutical or an experimental drug. While FDA 
broadened access to experimental drugs after the AIDS epidemic, clinical trial access remains limited and periodically patients sue. In January 2008, the US Supreme Court declined to take up the issue of whether terminally ill patients have a 'fundamental right' - protected by the US Constitution - of access to experimental drugs that have not yet been fully approved by the FDA, after a lower court in the District of Columbia refused to order access [41]. In 2008, a district court judge ordered a drug company to provide access to a clinical trial drug to a seriously ill patient who was not in the research protocol [42]. The case was reversed on appeal [43]. This, however, is not the end of the issue. With expanding populations of patients desperately needing treatment, issues relating to broadening access will continue and Congress may well intervene with a legislative solution, such as by Senator Brownback's 2008 proposed Access Act [44].

\subsection{Conclusions}

The FDA remains a conglomerate federal agency with various expanding consumer protection mandates for drugs and biologics, medical devices, animal drugs and foods. The diverse obligations keep the agency leadership struggling to maintain effective control and consumer protection over a constantly shifting set of emergencies and priorities. In a very real sense, it appears that the FDA is trying to do too much in disparate areas and that perhaps it is time to reconsider its structure and organization.

With more than 50 years of controversy surrounding FDA's regulation of drugs since the enactment of the 1962 Amendments to the Federal Food, Drug and Cosmetic Act, every expectation remains that controversy will continue unless Congress, FDA or the administration deliberately seek to change the structure and organization. During these 50 years, the FDA has not resisted expanding its regulatory turf even although its resources and management are insufficient for the FDA to perform adequately as reported by FDA's own Science Advisory Board Subcommittee. It has difficulty resisting new regulatory turf that does not fit well with its regulatory expertise and mandates, such as the newly enacted FDA regulation of tobacco (although clearly a serious public health concern, tobacco is very different from the medical products and foods that the FDA currently regulates).

The time has come for a serious consideration of how best to restructure the FDA's responsibilities. Medical products would form the basis of a reasonable regulatory agency - a medical products agency. A major portion of medical products are currently user-fee funded and it is not unreasonable to believe that industry would fund an even larger proportion of a streamlined, dedicated medical products agency. Well-managed medical product user fee agencies do well in other countries, and at significantly less cost and less subject to political pressure than FDA's current programs. While foods are outside the scope of this chapter, it should be noted that Congress seeks to greatly expand FDA's regulatory authority over food safety and there has been much discussion that FDA's food activities could find a better organizational home, possibly combined with other food regulatory responsibilities now at the US Department of Agriculture (USDA). 
Although the FDA Science Advisory Board Subcommittee urged a vast infusion of resources to improve science at FDA, it did not conduct a serious examination of the alternative ways a regulatory agency can or should gain the particular scientific expertise it requires to meet is regulatory responsibilities. The FDA basically needs to be able to manage a regulatory process that relies on science and should have staff skilled in gaining the necessary knowledge to make regulatory decisions and conduct market control.

It is unrealistic that a federal regulatory bureaucracy could and should have on its staff the best and brightest in all of the critical areas of knowledge necessary for the understanding and regulation of innovative medical products. The development of pharmaceuticals and their clinical testing has primarily been a private sector responsibility that relies on non-government scientific expertise. Other federal science and science-based regulatory agencies rely heavily on non-government experts to provide assistance on cutting-edge scientific areas. Even the NIH is based on a complex network of non-government grantee institutions and scientists, a host of federal advisory committees to review applications for grant applications and other advisory committees to oversee the work of the NIH. In other countries, medical product agencies typically rely on extensive networks of scientists and other medical experts, instead of seeking to have all of this expertise contained within the staff of the regulatory agency.

The FDA's Critical Path Initiative has added a major new role for the FDA. The agency has moved from being primarily a regulator for clinical trials and market access for new drugs to a resource for translating science into medical products (e.g. the Critical Path Initiative). A Los Angeles Times headline in 2000 asserted 'Once a wary watchdog, the Food and Drug Administration set out to become a 'partner' of the pharmaceutical industry. Today, the public has more remedies, but some are proving lethal' [45].

There are other good reasons to be cautious about how large a role the FDA should play in developing the tools sought for the critical path. The innovation driving the advances in medical products has come primarily from the private sector. Innovation by its very nature does not follow a simple cookbook formula, and the critical path could become an unproductive rut if it discourages the out-of-the-box thinking that will lead to innovative treatments and cures. The development of the critical path, or critical paths, should, to the extent possible, remain as innovative as the innovation that it hopes to engender. And for this, the ideal critical path may be outside of the government bureaucracy.

Drug cost and reimbursement issues are driving considerations of comparative effectiveness, cost-benefit, pharmacoeconomics and other paradigms aimed at improving value from drugs. The FDA currently operates at the edge of these considerations that are under the purview of other federal agencies. The movement to health care reform will be relying much more heavily on this type of information. The extent to which the FDA or other agencies take on major responsibilities to valuing pharmaceuticals will impact on what agencies will influence the climate for drug development and clinical trials. 
Finally, the growing and shifting pharmaceutical industry outside of the United States will impact the role, operation and influence of the FDA. This may prove to be the greatest challenge faced by the FDA, its structure and organization. Because of limitations on its ability to oversee research and manufacture offshore, the FDA will need to adapt new mechanisms, likely in concert with other drug regulatory agencies, for ways to protect American consumers and clinical trial subjects.

\section{References}

1. Mathieu, M. (2008) New Drug Development: A Regulatory Overview, 8th edn, PAREXEL, Waltham.

2. http://www.fda.gov/opacom/morechoices/mission.html (accessed 1 December 2008). FDA's Mission Statement: The FDA is responsible for protecting the public health by assuring the safety, efficacy, and security of human and veterinary drugs, biological products, medical devices, our nation's food supply, cosmetics and products that emit radiation. The FDA is also responsible for advancing the public health by helping to speed innovations that make medicines and foods more effective, safer and more affordable; and helping the public get the accurate, science-based information they need to use medicines and foods to improve their health.

3. Crosse, M. (2007) Drug Safety: Preliminary Findings Suggest Weaknesses in FDA's Program for Inspecting Foreign Drug Manufacturers, Testimony Before the Subcommittee on Oversight and Investigations, Committee on Energy and Commerce, House of Representatives, November 1 2007, United States Government Accountability Office, p. 1, http://www.gao.gov/new.items/d08224t.pdf (accessed 7 January 2009).

4. Quoted in Katzman, S. (1990) Deadly overcaution: FDA's drug approval process. Journal of Regulation and Social Costs, 35 (1), 41. Available at http://www.cei.org/ gencon/019,03887.cfm (accessed 7 January 2009).

5. Walker, S. (2005) Abagail Alliance for Better Access to Development Drugs Presentation, FDA Oncologic Drugs Advisory Committee, November 8 2005, http://abigailalliance.org/Nov_8_ODAC_STEVE_Presentation_Text_1_.doc (accessed 7 January 2009).

6. Leslie, L.K., Newman, T.B., Chesney, P.J. et al. (2005) The food and drug administration's deliberations on antidepressant use in pediatric patients. Pediatrics, http://pediatrics.aappublications.org/cgi/content/abstract/116/1/195 (accessed 7 January 2009).

7. Thaul, S. (2007) The Prescription Drug User Fee Act (PDUFA): Background and Issues for PDUFA IV Reauthorization, Congressional Research Service Report for Congress, March 13, 2007, p. 1, http://assets.opencrs.com/rpts/RL33914_20070313.pdf (accessed 7 January 2009).

8. Health Canada (2007) Cost Recovery Framework: International Comparison of Fees and Service Standards for Human Drugs, August 2007, http://www.hc-sc.gc.ca/dhp-mps/ pubs/finance/2007-crf-crc-drug-hum-med/index-eng.php (accessed 7 January 2009).

9. FDA Public Law 105-115 111 Stat. 2296 (1997) The FDA Modernization Act of 1997, http://www.fda.gov/opacom/backgrounders/modact.htm (accessed 7 January 2009).

10. Berndt, E.R., Gottschalk, A.H.B., Philipson, T., and Strobeck, M.W. (2004) Assessing the Impacts of the Prescription Drug User Fee Acts (PDUFA) on the FDA Approval Process. AEI-Brookings Joint Center for Regulatory Studies, Working Paper 04-19, 
October 2004, http://www.aei-brookings.org/admin/authorpdfs/redirect-safely.php?fname $=. . /$ pdffiles/phpIv.pdf (accessed 7 January 2009).

11. Sasich, L. Comments before the Food and Drug Administration's Public Meeting on the Prescription Drug User Fee Act (PDUFA), http://www.citizen.org/publications/release. cfm?ID=6737 (accessed 7 January 2009).

12. Sasich, L., Wolfe, S., Peck, B., and Clemente, F. (2002) Comments to FDA on the Prescription Drug User Fee Act (PDUFA), Public Citizen Health Group and Congress Watch, [Docket No. 01N-0450], January 25 2002, http://www.fda.gov/OHRMS/ DOCKETS/dockets/01n0450/01N-0450_emc-000003-01.doc (accessed 7 January 2009).

13. GAO (2002) Food and Drug Administration - Effect of User Fees on Drug Approval Times, Withdrawals, and Other Agency Activities, US Government Accounting Office, September 2002, http://www.gao.gov/new.items/d02958.pdf (accessed 7 January 2009).

14. George Washington University (2007) Reauthorizing the Prescription Drug User Fee Act: How are PDUFA, the FDA Budget, and Drug Safety Related? The School of Public Health and Health Services Rapid Public Health Project Response, April 2007, http:// www.gwumc.edu/sphhs/about/rapidresponse/download/RapidResponse_PDUFA.pdf (accessed 7 January 2009).

15. GAO (2006) Drug Safety: Improvement Needed in FDA's Postmarket Decision-making and Oversight Process, US Government Accountability Office, Washington, DC, March 2006, http://www.gao.gov/products/GAO-06-402 (accessed 7 January 2009).

16. Committee on the Assessment of the US Drug Safety System, Institute of Medicine (2007) The Future of Drug Safety: Promoting and Protecting the Health of the Public, National Academy of Sciences, Washington, DC.

17. Harris, G. (2007) Report Assails F.D.A. Oversight of Clinical Trials, New York Times (September 28, 2007), http://www.nytimes.com/2007/09/28/health/policy/28fda.html (access 7 January 2009).

18. (a) Carpenter, D., Bowers, J., Grimmer, J. et al. (2007) Deadline Effects in Regulatory Drug Review: A Methodological and Empirical Analysis, March 2007. Presented at Policy Workshop on Strengthening the FDA, Project on Scientific Knowledge and Public Policy, GW's School of Public Health and Health Services, February 22, 2007, Washington, DC, Unpublished, http://www.defendingscience.org/newsroom/upload/Carpenter_ FDA_Deadlines-2.pdf (accessed 7 January 2009); (b) Carpenter, D., Nardinelli, C., Lanthier, M. et al. (2008) FDA drug review and safety problems. The New England Journal of Medicine, 359, 95-98, http://content.nejm.org/cgi/content/full/359/1/95 (accessed 7 January 2009).

19. Calfee, J. (2007) Reform without Reason: What's Wrong with the FDA Amendments Act of 2007, Heath Policy Outlook, AEI Online, September 26, 2007, http://www.aei.org/ publications/pubID.26859/pub_detail.asp (accessed 7 January 2009).

20. Mahinka, S.P. (2007) How Are New Safety Concerns Affecting FDA Approvals and CMS Reimbursement of Bio/Pharma Products, November 7, 2007, http://www. morganlewis.com/pubs/Mahinka_SafetyConcernsAffectingFDA_Nov07.pdf (accessed 7 January 2009).

21. Zerhouni, E. (2003) Medicine: the NIH roadmap. Science, 302 (5642), 63-72, http://www.sciencemag.org/cgi/content/short/302/5642/63 (accessed 7 January 2009).

22. NIH (2004) The NIH Roadmap for Medical Research, http://nihroadmap.nih.gov/ initiatives.asp (accessed 7 January 2009).

23. FDA (2003) Improving Innovation in Medical Technology: Beyond 2002, http://www. fda.gov/bbs/topics/news/2003/beyond2002/execsumm.html (accessed 7 January 2009).

24. FDA (2004) Challenges and Opportunities on the Critical Path to New Medical Products, FDA, March 2004, p. ii, http://www.fda.gov/oc/initiatives/criticalpath/whitepaper.html (accessed 7 January 2009). 
25. Woodcock, J. (2007) FDA, Making Medical Products Better, Faster, and Cheaper - What FDA's Critical Path Initiative Means to Consumers, Q and A, FDA, September 7 2007, http://www.fda.gov/consumer/updates/criticalpath091007.html (accessed 7 January 2009).

26. Clinton, P. and Wechsler, J. (2006) What ever happened to critical path. Pharmaceutical Executive, http://pharmexec.findpharma.com/pharmexec/article/articleDetail.jsp?id= 282481\&page $\mathrm{ID}=1 \& \mathrm{sk}=\&$ date $=($ accessed 7 January 2009 $)$.

27. FDA (2009) http://www.fda.gov/oc/initiatives/criticalpath/reports/opp_list.pdf.

28. Report of the Subcommittee on Science and Technology (2007) FDA Science and Mission at Risk, November 2007.

29. Hyman, P. and McNamara, P.C. Public Law 110-185 121 Stat. 823 (2007) Food and Drug Administration Amendments Act of 2007, October 11 2007, http://www. hpm.com/pdf/HPM\%20FDAAA\%20Summary\%20and\%20Analysis.pdf (accessed 7 January 2009).

30. Thaul, S. (2007) The Prescription Drug User Fee Act (PDUFA): Background and Issues for PDUFA IV Reauthorization, Congressional Research Service Report for Congress, March 13, 2007, http://assets.opencrs.com/rpts/RL33914_20070313.pdf (accessed 7 January 2009) See, for example: Union of Concerned Scientists (2006) FDA Scientists Pressured to Exclude, Alter Findings; Scientists Fear Retaliation for Voicing Safety Concerns: Public Health and Safety Will Suffer without Leadership from FDA and Congress. Press release, July 20, 2006, at http://www.ucsusa.org/news/press_release/fda-scientistspressured.html; Text: Andrew, C. and Von Eschenbach, M.D. (2006) Confirmation Questions [from Senator Grassley] for the Record. FDA Week, 12 (48); and House Energy and Commerce Subcommittee on Oversight and Investigations Holds Hearing on Drug Safety, Congressional Transcripts, February 13, 2007, at http://www.cq.com.

31. Health Canada (2007) Cost Recovery Framework: International Comparison of Fees and Service Standards for Human Drugs, August 2007, http://www.hc-sc.gc.ca/dhp-mps/ pubs/finance/2007-crf-crc-drug-hum-med/index-eng.php (accessed 7 January 2009).

32. Orzag, P. (2007) Research on the Comparative Effectiveness of Medical Treatments: Options for an Expanded Federal Role, Testimony before the House Committee on Ways and Means Subcommittee on Health, June 12, 2007, http://www.cbo.gov/doc.cfm? index $=8209$ (accessed 7 January 2009).

33. Jacobson, GA. (2007) Comparative Clinical Effectiveness and Cost-Effectiveness Research: Background, History, and Overview, Congressional Research Service, October 15, 2007, http://assets.opencrs.com/rpts/RL34208_20071015.pdf (accessed 7 January 2009).

34. Orzag, P. (2007) Research on the Comparative Effectiveness of Medical Treatments: Options for an Expanded Federal Role, Testimony before the House Committee on Ways and Means Subcommittee on Health, June 12, 2007, http://www.cbo.gov/doc.cfm? index $=8209$ (accessed 7 January 2009).

35. Temple, R. (2008) Comparative Effectiveness - FDA Activities, presentation to the National Health Policy Forum, September 26, 2008, http://www.nhpf.org/handouts/ Temple.slides_09-26-08.pdf (accessed 7 January 2009).

36. Mann, D.L. and Siegfried, D.R. (2007) Why FDA Said No to Arcoxia. Arthritis Today Magazine (June 6, 2007), http://www.arthritis.org/arcoxia-not-approved.php (accessed 7 January 2009).

37. Peck, P. (2007) FDA Advisers Give Overwhelming Rejection to Etoricoxib (Arcoxia). Medpage Today (April 12, 2007), http://www.medpagetoday.com/ProductAlert/ Prescriptions/5433 (accessed 7 January 2009).

38. Akin, G., Strauss, H., and Feld, L.L.P. (2008) Court Rejects Medicare's "Least Costly Alternative" Drug Payment Policy in Hays v. Levitt'. Newsletters and Alerts 
(November 14, 2008) http://www.akingump.com/communicationcenter/newsalertdetail. aspx?pub=2014.

39. Riegel vs. Medtronic, Inc., WL 440744 (February 20, 2008).

40. Liptak, A. (2008) Justices Weigh Effect of F.D.A. Approval of Drug Labels on Suits in State Courts. New York Times (November 3, 2008).

41. Greenhouse, L. (2008) Justices Won't Hear Appeal on Drug for Terminally Ill. New York Times (January 15, 2008), http://www.nytimes.com/2008/01/15/washington/15appeal. html?_r=1\&scp=1\&sq=Abigail20Alliance\%20for\%20Better\%20Access $\% 20$ to $\% 20$ Developmental\%20Drugs\&st=cse (accessed on 7 January 2009).

42. Grynbaum, M. (2008) Judge Orders Drug Maker to Provide Experimental Treatment to Terminally Ill Teenager. New York Times (August 20, 2008), http://www.nytimes.com/ 2008/08/21/business/21dystrophy.html (accessed 7 January 2009).

43. Goldstein, J. (2008) Federal court denied teenager experimental muscular dystrophy drug. Wall Street Journal Health Blog, http://blogs.wsj.com/health/2008/12/17/federalcourt-denies-teen-experimental-muscular-dystrophy-drug/ (accessed 7 January 2009).

44. Senator, B., S.3046, 110th Congress, ACCESS Act, http://frwebgate.access.gpo.gov/ cgi-bin/getdoc.cgi?dbname $=110 \_$cong_bills\&docid=f:s3046is.txt.pdf $\quad$ (accessed 7 January 2009), also see http://abigail-alliance.org.

45. Willmann, D. (2000) How a New Policy Led to Seven Deadly Drugs. Los Angeles Times, December 20, 2000, http://articles.latimes.com/2000/dec/20/news/mn-5281 (accessed 7 January 2009). 